\title{
Lymphostin (LK6-A), a Novel Immunosuppressant from Streptomyces sp. KY11783:
}

\section{Structural Elucidation}

\author{
Yumiko Aotani, Hroyuki Nagata and Mayumi Yoshida* \\ Tokyo Research Laboratories, Kyowa Hakko Kogyo Co., Ltd., \\ 3-6-6 Asahimachi, Machida-shi, Tokyo 194, Japan
}

(Received for publication March 21, 1997)

\begin{abstract}
Lymphostin (LK6-A), a novel immunosuppressant, was isolated from the culture broth of Streptomyces sp. KY11783. Lymphostin showed potent inhibitory activity against the lymphocyte kinase, Lck ( $\mathrm{p} 56^{l k k}$ ). The structure of lymphostin was determined by spectroscopic methods to be a novel tricyclic aromatic alkaloid. A key feature of the structure is the pyrrolo[4,3,2-de]quinoline moiety which is rare among natural products.
\end{abstract}

We have isolated a potent immunosuppressant, lymphostin (LK6-A ${ }^{1)}$, Fig. 1), from the culture broth of Streptomyces sp. KY11783. Lymphostin inhibited the activity of the lymphocyte kinase, Lck ( $556^{l c k}$ ), with an $\mathrm{IC}_{50}$ value of $0.05 \mu \mathrm{M}$. In the preceding paper ${ }^{2)}$, fermentation, purification, and biological properties of lymphostin were reported. In this paper, we describe the details of its structure determination.

\section{Structural Elucidation}

The physico-chemical properties of lymphostin are summarized in Table 1. The UV spectrum indicated the presence of a polyaromatic system. The IR spectrum suggested the existence of a secondary amide and a ketone conjugated with double bonds. The molecular formula for lymphostin was established as $\mathrm{C}_{16} \mathrm{H}_{14} \mathrm{~N}_{4} \mathrm{O}_{3}$ by the HR-FAB-MS measurement, implying twelve degrees of unsaturation in the molecule.

In the ${ }^{1} \mathrm{H}$ NMR spectrum in dimethylsulfoxide- $d_{6}$ (DMSO- $d_{6}$ ), one methyl singlet $\left(\delta_{\mathrm{H}} 2.35\right)$, one $O$-methyl $\left(\delta_{\mathrm{H}} 3.94\right)$, three aromatic methine singlets $\left(\delta_{\mathrm{H}} 8.14, \delta_{\mathrm{H}}\right.$ $\left.8.39, \delta_{\mathrm{H}} 8.62\right)$, and a pair of coupled olefinic protons $\left(\delta_{\mathrm{H}}\right.$ $7.87, \delta_{\mathrm{H}} 7.64, J=12.6 \mathrm{~Hz}$ ) were observed. Also observ-

Fig. 1. Structure of lymphostin.<smiles>CO/C=C/C(=O)c1cc2c3c(c(N)cc(NC(C)=O)c3n1)N=C2</smiles>

ed were two additional broad signals at $\delta_{\mathrm{H}} 8.21$ (two protons) and at $\delta_{\mathrm{H}} 10.14$ (one proton). According to the molecular formula and the IR spectrum, they were assigned to an amino and an amide proton respectively.

The ${ }^{13} \mathrm{C}$ NMR (DMSO- $d_{6}$ ) spectrum showed all sixteen signals and the DEPT experiments revealed the presence of two methyls, five methines and nine quarternary carbons. Direct ${ }^{13} \mathrm{C}-{ }^{1} \mathrm{H}$ connectivities were established by HSQC (Heteronuclear Single Quantum Coherence) experiment. The quarternary carbons at $\delta_{\mathrm{C}}$ 188.7 and $\delta_{\mathrm{C}} 169.7$ should be assigned to a conjugated carbonyl carbon and an amide carbonyl carbon respectively, considering the results of the UV and the IR spectra. One of the methines was assumed to be adjacent to a nitrogen atom in a pyrrol ring based on its chemical shifts $\left(\delta_{\mathrm{C}} 145.8, \delta_{\mathrm{H}} 8.39\right)$ and a large ${ }^{1} J_{\mathrm{CH}}$ coupling constant $(190 \mathrm{~Hz})$.

Complete ${ }^{1} \mathrm{H}$ and ${ }^{13} \mathrm{C}$ NMR assignments obtained from analyses of one and two dimensional NMR experiments are exhibited in Table 2. Connectivities between structural elements were mainly established with

Table 1. Physico-chemical properties of lymphostin.

\begin{tabular}{ll} 
MP & $275 \sim 277^{\circ} \mathrm{C}$ \\
Molecular weight & 310 \\
Molecular formula & $\mathrm{C}_{16} \mathrm{H}_{14} \mathrm{~N}_{4} \mathrm{O}_{3}$ \\
FAB-MS $(m / z)$ & $311[\mathrm{M}+\mathrm{H}]^{+}$ \\
HRFAB-MS $(m / z)$ & \\
Observed & $311.1137[\mathrm{M}+\mathrm{H}]^{+}$ \\
Calcd & 311.1144 \\
UV $\lambda_{\max }^{\mathrm{CH}_{3} \mathrm{CN}} \mathrm{nm}(\varepsilon)$ & $467(8,200), 412(6,000)$ \\
& $344(11,900), 284(16,000)$ \\
& $256(19,300), 218(15,200)$ \\
IR $v_{\max }(\mathrm{KBr}) \mathrm{cm}^{-1}$ & $3367,1671,1659,1633,1595,1506$ \\
& $1362,1350,1236,1128,1076$ \\
\hline
\end{tabular}


Table 2. ${ }^{13} \mathrm{C}$ and ${ }^{1} \mathrm{H}$ NMR data of lymphostin in DMSO- $d_{6}$.

\begin{tabular}{ccc}
\hline Position & $\begin{array}{c}\delta_{\mathrm{C}}(\mathrm{m}) \\
{[125 \mathrm{MHz}]}\end{array}$ & $\begin{array}{c}\delta_{\mathrm{H}}(\mathrm{m}, J \mathrm{in} \mathrm{Hz}) \\
{[500 \mathrm{MHz}]}\end{array}$ \\
\hline 2 & $145.8(\mathrm{~d})$ & $8.39(\mathrm{~s})$ \\
$2 \mathrm{a}$ & $136.6(\mathrm{~s})$ & $8.62(\mathrm{~s})$ \\
3 & $117.6(\mathrm{~d})$ & \\
4 & $147.7(\mathrm{~s})$ & \\
$5 \mathrm{a}$ & $133.5(\mathrm{~s})$ & \\
6 & $139.5(\mathrm{~s})$ & \\
7 & $110.8(\mathrm{~d})$ & \\
8 & $150.3(\mathrm{~s})$ & \\
$8 \mathrm{a}$ & $124.9(\mathrm{~s})$ & \\
$8 \mathrm{~b}$ & $124.4(\mathrm{~s})$ & \\
9 & $188.7(\mathrm{~s})$ & $7.64(\mathrm{~d}), 12.6)$ \\
10 & $101.9(\mathrm{~d})$ & $7.87(\mathrm{~d}, 12.6)$ \\
11 & $163.9(\mathrm{~d})$ & $3.94(\mathrm{~s})$ \\
12 & $58.5(\mathrm{q})$ & \\
13 & $169.7(\mathrm{~s})$ & $2.35(\mathrm{~s})$ \\
14 & $24.5(\mathrm{q})$ & $10.14(\mathrm{~s})$ \\
$6-\mathrm{NH}_{-}$ & & $8.21(\mathrm{~s})$ \\
$8-\mathrm{NH}_{2}$ & & \\
\hline
\end{tabular}

$\delta:$ ppm from TMS, m: multiplicity.

HMBC experiment (Fig. 2). The $O$-methyl proton $\mathrm{H}-12$ $\left(\delta_{\mathrm{H}} 3.94\right)$ showed long range ${ }^{13} \mathrm{C}^{1}{ }^{1} \mathrm{H}$ coupling with the olefinic methine carbon $\mathrm{C}-11\left(\delta_{\mathrm{C}} 163.9\right)$ and the two olefinic methine protons $\mathrm{H}-10$ and $\mathrm{H}-11\left(\delta_{\mathrm{H}} 7.64, \delta_{\mathrm{H}}\right.$ 7.87) had long range couplings with the carbonyl carbon $\mathrm{C}-9\left(\delta_{\mathrm{C}} 188.7\right)$, indicating the presence of a $\beta$-methoxy enone stucture. The geometry of the double bond was determined to be $E$-configuration from the result of NOESY experiment, in which $O$-methyl proton $\mathrm{H}-12$ had a correlation to $\mathrm{H}-10$ as well as to H-11. Also indicated was the presence of an acetamido structure, from the observation of correlations of the amide carbonyl carbon $\mathrm{C}-13\left(\delta_{\mathrm{C}} 169.7\right)$ to the methyl proton $\mathrm{H}-14\left(\delta_{\mathrm{H}} 2.35\right)$ and to the amide proton $\left(\delta_{\mathbf{H}}\right.$ 10.14). These two structures were supposed to be the side chains of the polyaromatic moiety of lymphostin. Although the rest of the HMBC information (Fig. 2) allowed definition of several other partial structures, it was not enough to determine the whole structure because of the ambiguity of three versus four bond couplings in the HMBC experiments. Therefore, we added $\mathrm{CD}_{3} \mathrm{OD}-\mathrm{CD}_{3} \mathrm{OH}(1 ; 1)$ solvent to the DMSO- $d_{6}$ solution of lymphostin in order to obtain deuterium shift information in ${ }^{13} \mathrm{C} N \mathrm{NM}$ spectra. In that experiment, several carbon signals showed a characteristic high field shift ${ }^{3)}$, which led us to construct the structure in the vicinity of labile protons as shown in Fig. 3. The remained partial structures were connected according to other long range ${ }^{13} \mathrm{C}-{ }^{1} \mathrm{H}$ couplings (Fig. 2). The structure of lymphostin in Fig. 1 was finally determin-
Fig. 2. ${ }^{1} \mathrm{H}^{-13} \mathrm{C}$ long range couplings of lymphostin.

Arrows are directing $\mathrm{H}$ to $\mathrm{C}$.

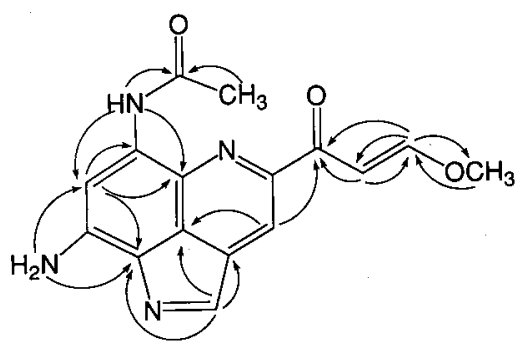

Fig. 3. Partial structure of lymphostin.

Numbers are ${ }^{13} \mathrm{C}$ NMR chemical shifts. Underlined numbers are ${ }^{13} \mathrm{C}$ NMR chemical shifts of deuterized lymphostin.

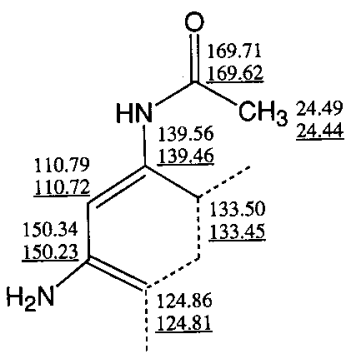

ed after conducting a differential NOE experiment, in which we found an important NOE correlation between aromatic methines $\mathrm{H}-2\left(\delta_{\mathrm{H}} 8.39\right)$ and $\mathrm{H}-3\left(\delta_{\mathrm{H}} 8.62\right)$.

\section{Discussion}

Lymphostin was determined to be a novel tricyclic aromatic alkaloid with a pyrrolo[4,3,2-de]quinoline skeleton. The high unsaturation of the structure needed analyses of the various NMR spectroscopic experiments until the structure determination was achieved.

This fused aromatic ring system is rare among natural products. The plakinidines ${ }^{4,5)}$ are the only natural compounds reported to possess the pyrrolo[4,3,2-de]quinoline system. Plakinidine A was reported to have reverse transcriptase inhibiting activity, anti-parasite activity and cytotoxity to L1210. Plakinidine B and C were also reported to have one or two of these activities. However, they have not been reported to inhibit any protein kinase activities. Further investigation of the activities of the novel compound, lymphostin, will definitely provide substantial information for the development of protein kinase inhibitors. 


\section{Experimental}

The melting point was determined with a Yanagimoto melting point apparatus. The FAB-MS spectrum was measured with a JEOL JMS-HX/HX110A mass spectrometer. The UV spectrum was recorded on a Shimadzu UV-2200 spectrometer. The IR spectrum was taken on a JEOL JIR-RFX3001 spectrometer. The NMR spectra were recorded on a Bruker AM500 spectrometer or a JEOL A-400 using TMS as an internal standard.

\section{Acknowledgements}

We would like to thank Mr. Shingo Kakita, Ms. Rirsuko KaTAHIRA and Ms. Yuko UOSAKI for NMR experiments and Ms. Kiyomi Yoshikawa for measurements of some physicochemical properties.

\section{References}

1) Tamaoki, T.; H. Nagata, I. Takahashi, M. Yoshida, Y. Aotani, K. Ando \& K. Ochial (Kyowa Hakko Kogyo Co., Ltd.): Pyrrolo(4,3,2-de)quinoline derivative. JP 250276/95, Sep. 28, 1995

2) Nagata, H.; K. Ochiai, Y. Aotani, K. Ando, M. Yoshida, I. TAKAHASHI \& T. TAMAOKI: Lymphostin (LK6-A), a novel immunosuppressant from Streptomyces sp. KY11783. Taxonomy of the producing organism, fermentation, isolation and biological activities. J. Antibiotics 50: 537 542, 1997

3) Pfeffer, P. E.; K. M. Valentine \& F. W. Parrish: Deuterium-induced isotope shift ${ }^{13} \mathrm{C}$ NMR. J. Am. Chem. Soc. 101: $1265 \sim 1274,1979$

4) Inman, W. D.; M. O'Neill-Johnson \& P. Crews: Novel marine sponge alkaloids. 1. Plakinidine $\mathrm{A}$ and $\mathrm{B}$, anthelmintic active alkaloids from a Plakortis sponge. $\mathrm{J}$. Am. Chem. Soc. 112: 1 4, 1990

5) Brinen, L. S. \& J. Clardy: Plakinidines: Cytotoxic alkaloid from the fijian sponge Plakortis sp. Tetrahedron Lett. 31: $3271 \sim 3274,1990$ 